\title{
Predicting Biofuel Invasiveness: A Relative Comparison to Crops and Weeds
}

\author{
Larissa L. Smith, Daniel R. Tekiela, and Jacob N. Barney*
}

\begin{abstract}
Concern raised against using highly competitive, exotic, large-statured, perennial grasses with fast growth rates as bioenergy crops has led to calls for risk assessment before widespread cultivation. Weed risk assessments (WRAs) are decision support tools commonly used throughout the world to determine the invasion risk of new plant taxaprimarily used as a pre-entry screen. Here, we compare the common Australian (A-WRA) and newer U.S. (US-WRA) models to evaluate the invasion risk of 16 candidate bioenergy crops and to compare their WRA scores to 14 important agronomic crops and 10 invasive species with an agronomic origin. Of the 40 species assessed, the A-WRA and US-WRA ranked 34 and 28 species, respectively, as high risk, including the major crops alfalfa, rice, canola, and barley. Surprisingly, in several cases, both models failed to effectively parse weeds from crops. For example, cereal rye received scores above (US-WRA) or comparable to (A-WRA) kudzu, a widespread damaging invader of the Southeastern United States introduced as forage. Our results indicate that these models are unable to accurately address broad, intraspecific variation and that species introduced for agronomic purposes pose special limitations to WRAs. This further supports other calls for postborder evaluation (e.g., field testing) following WRA screening. We should be cautious of the role of WRAs in setting policy, as illustrated by this relative evaluation of novel crops.

Nomenclature: Kudzu, Pueraria montana var. lobata (Willd.) Maesen \& S.M. Almeida; cereal rye (Secale cereale L.); alfalfa, Medicago sativa L.; barley, Hordeum vulgare L.; canola, Brassica napus L.; rice, Oryza sativa L.
\end{abstract}

Key words: Bioenergy, invasive species, weed risk assessment.

Invasive species are found on every continent and affect nearly every landscape globally (Molina-Montenegro et al. 2012). Most of our worst invasive plants were intentionally introduced, cultivated, and dispersed (Simberloff 2008) and cause widespread, and sometimes irreversible, ecosystem change (Pimentel et al. 2000; Vilà et al. 2011). When driving down many roads in the southeastern United States, the catastrophic intentional introductions of species, such as kudzu [Pueraria montana var. lobata (Willd.) Maesen \& S.M. Almeida] and johnsongrass [Sorghum halepense (L.) Pers.], serve as reminders of our historic cavalier approach to species introduction. Once invasive plants become established and widespread, eradication is generally not practical or successful (McNeely et al. 2003; Panetta 2009), necessitating screening procedures to assess invasion risk before new species are widely introduced. Preborder decision-support tools have been adopted in many parts of the world (Cousens 2008; Hulme 2012).

\footnotetext{
DOI: 10.1614/IPSM-D-15-00001.1

${ }^{*}$ Graduate Student, Graduate Student, and Assistant Professor, Department of Plant Pathology, Physiology and Weed Science, Virginia Tech, Blacksburg, VA 24061, USA. Corresponding author's E-mail address: jnbarney@vt.edu
}

Unlike traditional, domesticated crops, bioenergy crops are selected for their rapid aboveground biomass production, low input requirements, broad climatic suitability, and performance on marginal land (Lewandowski et al. 2003); traits shared by many of our worst invasive plants (Raghu et al. 2006). For example, giant reed (Arundo donax L.), a noxious weed in four U.S. states (Quinn et al. 2013), lines the banks of the Rio Grande River in Texas, where it is the focus of an active biocontrol program (Seawright et al. 2009), yet some propose plantations in the southeastern United States (http://www.biofuelscenter.org/feedstocks/ energy-grasses? showall $=18$ limitstart $=$ ). Giant Miscanthus [Miscanthus $\times$ giganteus J.M. Greef $\&$ Deuter ex Hodkinson \& Renvoize], formerly known only as a sterile (triploid) hybrid of the invaders eulaliagrass (Miscanthus sinensis Anderss.) and Amur silvergrass [Miscanthus sacchariflorus (Maxim.) Franch.] (Dougherty et al. 2014), now includes a fertile (tetraploid) line that can produce an estimated 1.3 billion spikelets $\mathrm{ha}^{-1} \mathrm{yr}^{-1}$ (3.21 billion spikelets $\left.\mathrm{ac}^{-1} \mathrm{yr}^{-1}\right)$ (Smith et al. 2015) - a clear enhancement of its escape potential. The U.S. Department of Agriculture (USDA) Biomass Crop Assistance Program has already subsidized the establishment of $>42,000$ ha of biomass feedstocks, $22 \%$ of which are exotics. Future projections of a cultivated area 1.4 times the size of California (Robertson et al. 2008) 


\section{Management Implications}

The U.S. bioenergy industry seeks to cultivate dedicated energy crops to meet increasing demands for bio-based energy sources. Many of these potential crops are not native to the United States and are large-statured, perennial species with fast growth rates that effectively compete with resident vegetation-all traits shared by many invasive plants. Therefore, there have been repeated calls to prevent the introduction and wide cultivation of invasive species for bioenergy. One method widely used to identify the invasion risk of new species are weed risk assessments, with the Australian (A-WRA) and United States (US-WRA) versions being the most widely used. To identify the invasion risk of bioenergy crops, we compared their A-WRA and US-WRA scores to those of the 14 of the most-common agronomic crops and 10 invasive species originally introduced for agriculture. This allowed us to compare the biofuels to crops, which we expected to have low WRA scores and to known invaders, which we expected to have high WRA scores. Both WRAs found most species to be high risk, including many crops. The WRAs suffer from many limitations, including being unable to deal with species that include high intraspecific variation, like Sorghum bicolor, which is both a crop and weed. Therefore, WRAs should be used cautiously in setting policy, even when only serving as the first tier of a multistep, risk-assessment process.

presents opportunity for widespread invasion without careful risk assessment and mitigation.

In the case of economically important new crops, such as bioenergy feedstocks, the ability to distinguish invaders from noninvaders is imperative and has broad social, economic, environmental, and biosecurity implications (Cousens 2008). Much like the forage improvement programs in Australia and elsewhere, the bioenergy industry could provide substantial economic gain and enhance national security (Robertson et al. 2008). However, lacking precautionary forethought, the introduction of forages has resulted in numerous weedy escapes, $23 \%$ of which have become serious environmental weeds (Virtue et al. 2004), and may continue to get worse (Driscoll et al. 2014). Humans have been introducing exotic species since the invention of agriculture, but the land area proposed for novel bioenergy crop cultivation reaches a scale that concerns many (Barney and DiTomaso 2008; Raghu et al. 2006). Thus, the adoption of biosecurity tools is necessary to limit entry and widespread planting of damaging plants (e.g., Pheloung et al. 1999; Stone et al. 2008).

Historically, the U.S. policy regarding species introductions has largely been seen as arbitrary and subjective (Simberloff 2005), which is reflected in weak noxious weed policies (Eiswerth and Van Kooten 2000; Quinn et al. 2013). In contrast, Australia uses stringent preintroduction and quarantine procedures (Pheloung et al. 1999; Stone et al. 2008). In an effort to reduce the spread and environmental impact of exotic introductions, Australia has been a leader in the development of weed risk assessment (WRA) tools, which are used to determine whether or not to allow importation of an exotic species (Stone et al. 2008). The Australian WRA (A-WRA) has become the global standard (Pheloung et al. 1999). The recent USDA Plant Protection and Quarantine WRA (US-WRA) is the new regulatory benchmark in the United States, which is based on the A-WRA (Koop et al. 2012). The ability to parse the weeds from benign species seems a foreboding task, yet these tools boast $>90 \%$ accuracy in predicting which species have high invasive potential (Gordon et al. 2008). The broad adoption of scientifically backed assessments rooted in ecological principles could add consistency across federal and state regulatory agencies, while preventing environmental degradation, alleviating economic losses, and helping to target critical management practices (Quinn et al. 2013). However, these widely used tools are not without criticism (Hulme 2012; Lonsdale 2011).

WRA models have been criticized for their subjective nature, coupled with their disregard for low base rates $(<0.1 \%$ of introductions become invasive (Williamson and Fitter 1996)). Hulme (2012) argues that "[t]he accuracy of weed risk assessment protocols is usually insufficient, given inherent low base-rates even when the costs and benefits of decisions are taken into account, and implies that the predictive value of weed risk assessment is questionable." Some of the Hulme (2012) criticisms have been addressed in the newer US-WRA, including uncertainty and acknowledgement of base rates (Koop et al. 2012). Despite known limitations, WRAs are commonly used decision support tools (Cousens 2008; Davis et al. 2010; Koop et al. 2012; Quinn et al. 2013), making evaluation of their principles, implementation, and limitations vital.

Invasiveness is not universal for all populations of a species in all geographic locations, and all taxa have some nonzero probability of becoming invasive under the "right plant, right place, right time” axiom (Barney and Whitlow 2008). Therefore, all species exist along a spectrum of invasiveness, which varies based on the receiving environment (Smith and Barney 2014). In general, many exotic agronomic crops, such as corn (Zea mays L.) and soybeans [Glycine max (L.) Merr.], are thought of as having a low invasiveness probability (Martin et al. 2006). Conversely, previous agricultural introductions, such as johnsongrass and kudzu, are highly competitive species with invasive populations across the southeastern United States (Holm et al. 1977; Warwick and Black 1983). Thus, relative comparisons of taxa within an introduction pathway (e.g., agriculture) would aid interpretation and best identify strengths and weaknesses of WRAs by identifying clear, testable predictions (e.g., corn should have a low WRA score).

WRAs can be useful tools for evaluating invasion risk under many scenarios. With numerous U.S. states 
contemplating adoption of the US-WRA methodology for screening plants and updating noxious weed lists (Barney 2014), and the recent suggestion to use WRAs in the creation of "white lists" (Quinn et al. 2015), further evaluation of WRA use for agricultural crops is prudent. Others have commented on the role of WRAs for bioenergy (Barney 2014; Cousens 2008; Davis et al. 2010), but none have examined the potential limitations of the WRAs when applied to crops. Therefore, here, we evaluate leading candidate bioenergy crops for their potential to be invasive in the United States, using the A-WRA and US-WRA, and compare with well-established crops and species introduced for agriculture that have become invasive species. We hypothesized that agronomically introduced invasives would be rejected (have high risk), whereas crops undergoing centuries of domestication would be low risk, with bioenergy crops falling in between.

\section{Materials and Methods}

We compared the invasive potential, as determined by A-WRA and the US-WRA, of candidate bioenergy crops to well-established agronomic crops and invasive plants of agronomic origin (Table 1). We selected 16 leading bioenergy crops, which included large-statured perennial and annual grasses, short-rotation trees, and oil-crop species-all profiled as the taxa most likely to be used for bioenergy in the United States (Glaser and Glick 2012; Perlack et al. 2005). We performed two separate WRAs for Miscanthus $\times$ giganteus, sterile and fertile, because both are possible, unique bioenergy crops, yielding 17 bioenergy assessments. Recent studies have shown the importance of comparing species that vary in their known invasiveness (Buddenhagen et al. 2009; Smith and Barney 2014; Smith et al. 2015). We chose 14 of the most-common agronomic crops [e.g., corn, wheat (Triticum aestivum L.), and tobacco (Nicotiana tabacum L.)] - all of which have a long and well-documented cropping history in the United States (Martin et al. 2006) — to serve as so-called negative controls because we hypothesized they would have low WRA scores. We also identified 10 invasive species of agronomic origin, such as cogongrass [Imperata cylindrica (L.) Beauv], S. halepense, and $P$. montana), to serve as positive controls because we hypothesized they would have high WRA scores since they are all well-known invasive plants. In this framework we are comparing a variety of taxa, all of which were (or will be) introduced and cultivated for agricultural purposes.

Scoring and methodology for both the A-WRA, which has been widely and successfully tested on five continents and numerous geographic regions (Daehler et al. 2004; Gordon et al. 2008, 2010; Nishida et al. 2009; Pheloung et al. 1999), and the relatively new US-WRA have been thoroughly described in the literature (Koop et al. 2012).
Therefore, we only provide a brief description of both models and their scoring. For the A-WRA, we followed the detailed outline in Gordon et al. (2010). For the US-WRA, we followed Koop et al. (2012) as well as an intensive weeklong training program at the Plant Epidemiology and Risk Analysis Laboratory in Raleigh, NC, attended by L.L.S. and J.N.B. The A-WRA uses an additive design, comprising 49 yes/no questions on the topics of biogeographical and historical accounts (i.e., current geographic and habitat distribution, history of domestication, and status as a weed elsewhere in the world) and biology and ecology (i.e., species traits, reproduction, dispersal mechanisms, and persistence attributes) (Gordon et al. 2008; Pheloung et al. 1999). The US-WRA was created using the A-WRA as a template and incorporates a new set of questions, designed to assess regional impacts in three types of biological systems: natural environments, anthropogenic systems, and production systems (Koop et al. 2012). The US-WRA generates Establishment/Spread and Impact scores, which yield an integrated outcome score (Koop et al. 2012). Each response receives an uncertainty rating, based on the availability and quality of supporting information specified by the analyst. Monte Carlo simulations use these uncertainty ratings to generate confidence intervals around each score. The model also incorporates an automatic secondary-screening process, when further evaluation is needed (Koop et al. 2012).

We conducted an extensive literature survey for each species over the course of $2 \mathrm{yr}$. We evaluated each taxon at the species level, meaning any information for that species, including cultivars or feral populations, was included (see Barney et al. [2015] for the effect of modifying domestication and sterility on WRA scores). All available data were documented and incorporated into each model and used to generate scores with both the A-WRA and the US-WRA. When clear answers to each question were not available, we answered "?" with maximum uncertainty for the US-WRA, or left the question blank for the A-WRA, as a nonanswer does not influence the additive-based scoring of the A-WRA. Our evaluation was conducted for the continental United States. Both models require some level of geographic climate matching. Therefore, we used three variables to determine regions of the United States that would be suitable for establishment of each taxon. Data from the USDA Plant Hardiness Zones (NAPPFAST, ZedX Inc.), Köppen-Geiger climate classes (Peel et al. 2007), and annual precipitation data (NAPPFAST) were matched with coordinates of species occurrence records in both the native and introduced range. Current distribution maps for each species were accessed using the Global Biodiversity Information Facility (http://www.gbif.org).

We did not assess expert opinion nor analyst variability on WRA scores as some have done (e.g., Cousens 2008; Pheloung et al. 1999) because of the inherent large 


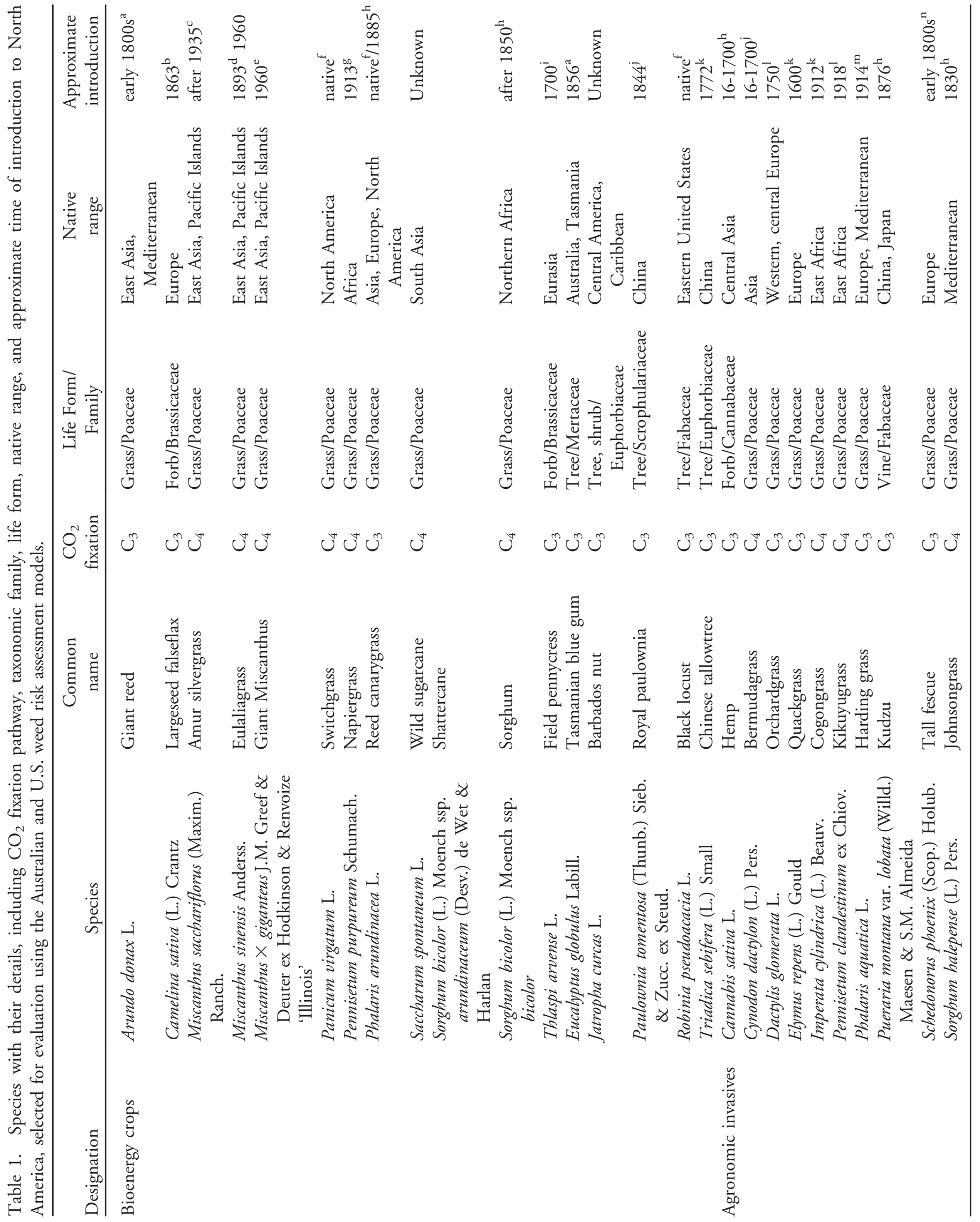




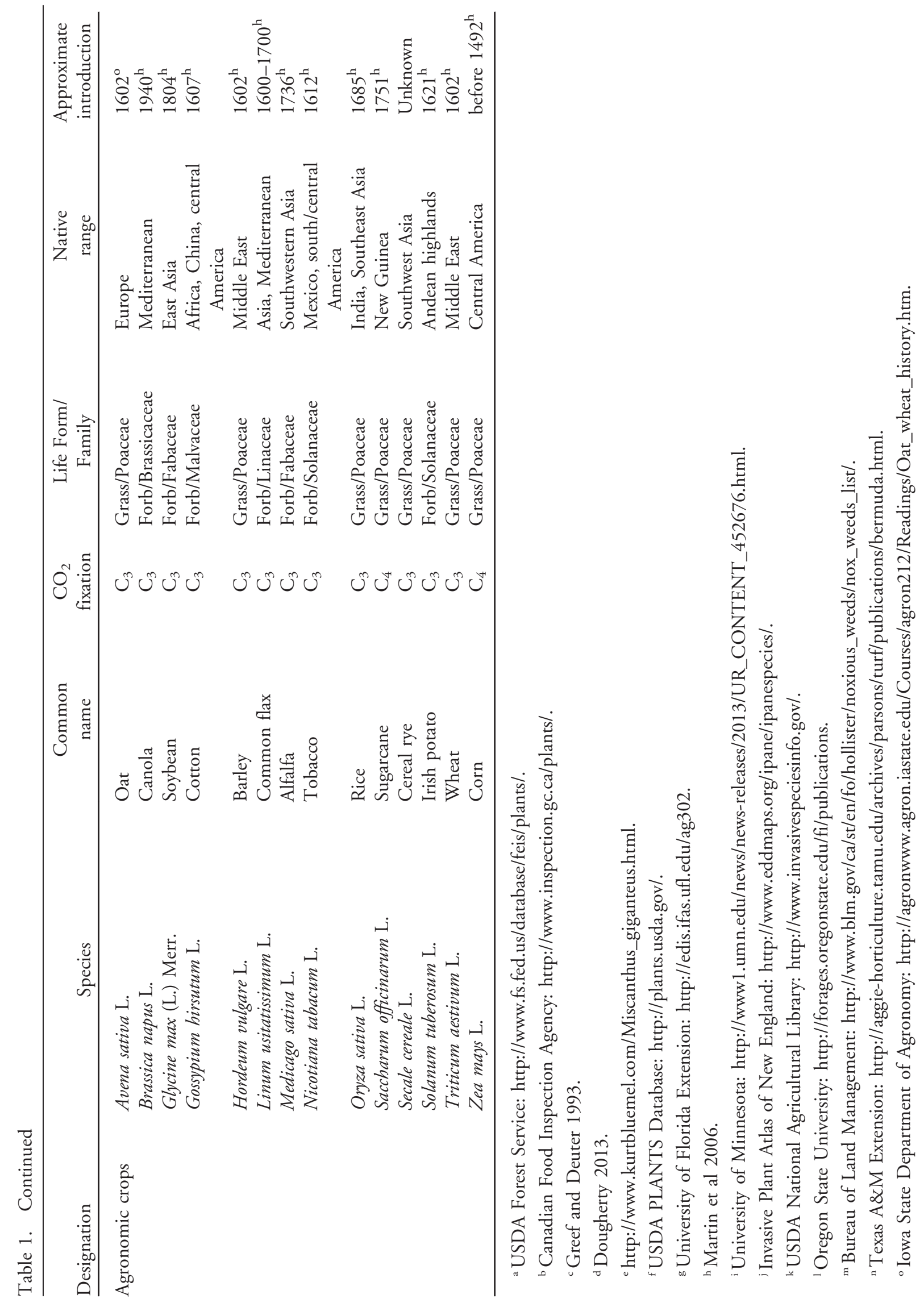


variability in expert opinions. For example, Cousens (2008) found that scores for canola ranged from 1 to 19 , with none reaching an "accept" decision. Thus, as Cousens (2008) concludes, adding "expert" opinion only adds variation, but it does draw attention to the subjective interpretations of WRA questions. For this study, we made assessments independently and then collectively, while documenting justification for all answers (Koop et al. 2012).

Because ecological impact should be central to invasiveness evaluation and management prioritization (Barney et al. 2013; Lewis and Porter 2014), we hypothesized that taxa with long residence times would have greater effects than more recently introduced taxa (Dostál et al. 2013). To test this, we performed linear regression analyses between the US-WRA impact scores and time since introduction (Table 1). We also performed linear regression of the US-WRA impact score against the total number of data source references for each species in the Global Compendium of Weeds (GCW), which has been used as a proxy for global invasiveness (e.g., Dawson et al. 2013). We hypothesized that species with more references (i.e., more-common invasives) would have higher impact scores.

\section{Results}

It was our goal to compare the A-WRA and US-WRA scores of species in three groups within one introduction pathway-agriculture: candidate bioenergy crops; agronomically introduced invasives; and long-established and economically important agronomic crops. As predicted, all of the invasives received a "high risk" or "reject" from the US-WRA and A-WRA tools (Table 2). We found that 16 of the 17 bioenergy crop assessments resulted in a rejection from the A-WRA; only sterile Miscanthus $\times$ giganteus received an outcome of "evaluate further" (Table 3). However, the US-WRA predicted that 13 of the bioenergy crops were "high risk," 3 still required further evaluation after the secondary screening or may just have minor invasive potential, and sterile Miscanthus $\times$ giganteus was predicted to be a low risk (Table 3). Surprisingly, of the 14 crops evaluated, only corn, cotton, and soybean were identified as low risk/acceptable by both models (Table 2). The A-WRA rejected 9 of 14 crops, and the US-WRA found 4 of those crops "high risk" as well. All other crops were classified as needing further evaluation.

It is clear that the A-WRA is the more-conservative model (Tables 2 and 3), accepting only 3 of the 40 species.

Table 2. Weed risk assessment scores and results for intentionally introduced agronomic invasives and crops, using the U.S. (USWRA) and the Australian (A-WRA) models.

\begin{tabular}{|c|c|c|c|c|c|}
\hline \multirow[b]{2}{*}{ Designation } & \multirow[b]{2}{*}{ Scientific name } & \multirow[b]{2}{*}{ Common name } & \multicolumn{2}{|c|}{ US-WRA } & \multirow[b]{2}{*}{ A-WRA result } \\
\hline & & & Result & Secondary screening & \\
\hline \multirow[t]{10}{*}{ Agronomic invasives } & Cannabis sativa & Hemp & Evaluate further & High risk & Reject \\
\hline & Cynodon dactylon & Bermudagrass & High risk & - & Reject \\
\hline & Dactylis glomerata & Orchardgrass & High risk & - & Reject \\
\hline & Elymus repens & Quackgrass & High risk & - & Reject \\
\hline & Imperata cylindrica & Cogongrass & High risk & - & Reject \\
\hline & Pennisetum clandestinum & Kikuyugrass & High risk & - & Reject \\
\hline & Phalaris aquatica & Harding grass & Evaluate further & High risk & Reject \\
\hline & Pueraria montana & Kudzu & High risk & - & Reject \\
\hline & Schedonorus arundinaceus & Tall fescue & High risk & - & Reject \\
\hline & Sorghum halepense & Johnsongrass & High risk & - & Reject \\
\hline \multirow[t]{14}{*}{ Agronomic crops } & Avena sativa & Oats & Evaluate further & Evaluate further & Reject \\
\hline & Brassica napus & Canola & High risk & - & Reject \\
\hline & Glycine max & Soybean & Low risk & - & Accept \\
\hline & Gossypium hirsutum & Cotton & Low risk & - & Accept \\
\hline & Hordeum vulgare & Barley & High risk & - & Reject \\
\hline & Linum usitatissimum & Flax & Evaluate further & Evaluate further & Reject \\
\hline & Medicago sativa & Alfalfa & High risk & - & Reject \\
\hline & Nicotiana tabacum & Tobacco & Low risk & - & Evaluate further \\
\hline & Oryza sativa & Rice & High risk & - & Reject \\
\hline & Saccharum officinarum & Sugarcane & Evaluate further & Evaluate further & Evaluate further \\
\hline & Secale cereale & Rye & High risk & - & Reject \\
\hline & Solanum tuberosum & Potato & Evaluate further & Evaluate further & Reject \\
\hline & Triticum aestivum & Wheat & Evaluate further & Evaluate further & Reject \\
\hline & Zea mays & Maize & Low risk & - & Accept \\
\hline
\end{tabular}

328 - Invasive Plant Science and Management 8, July-September 2015 


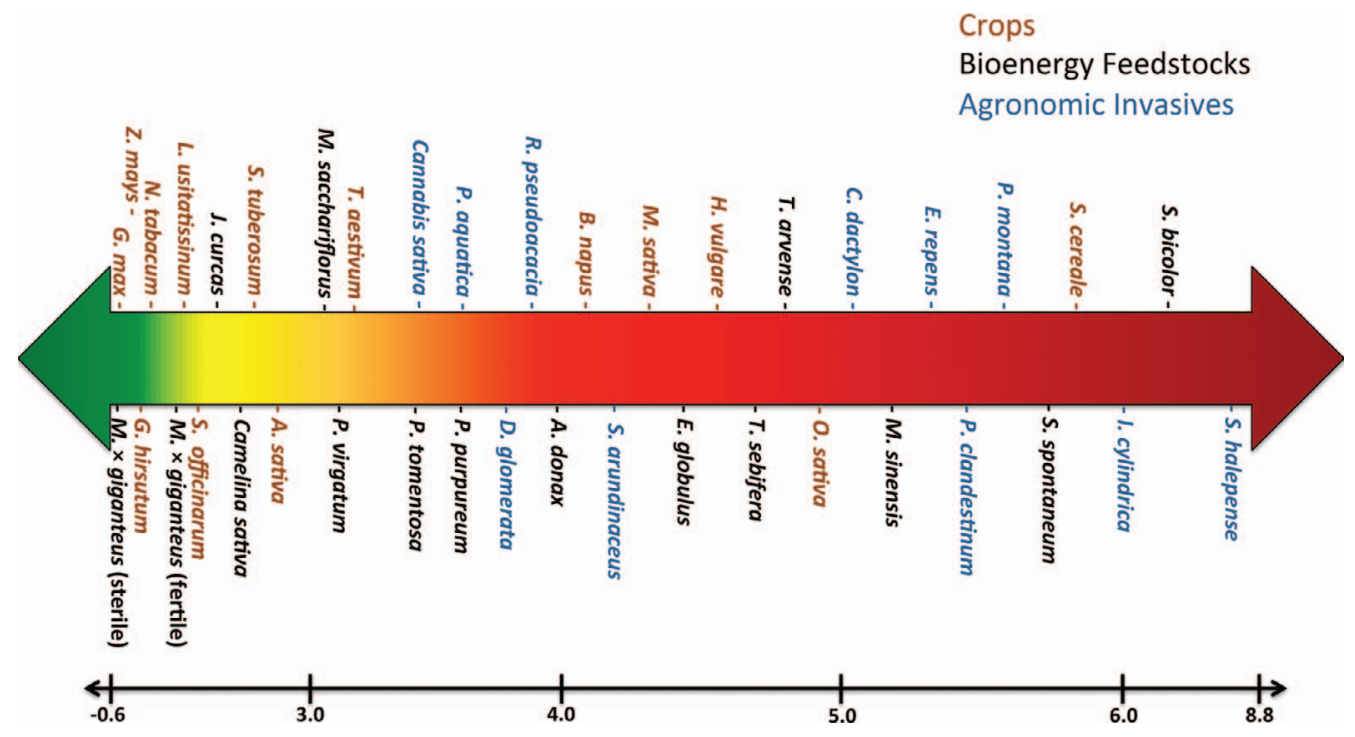

Figure 1. Distribution of U.S. weed risk assessment (US-WRA) scores. The spectrum of US-WRA scores for 40 species in three species designations: crops, bioenergy crops, or agronomic invasive. The scale indicating the range of composite risk scores from -0.6 to 8.8 is shown just below the spectrum. (Color for this figure is available in the online version of this paper.)

Contrary to our expectations, we observed a spectrum of scores with species from each of the three categories spanning all risk categories (Figure 1). We found no relationship between time since introduction or GCW references with US-WRA impact scores $(\mathrm{P}>0.05)$. This is not entirely surprising because the GCW indicates introduction rather than establishment, and we did not account for distribution or abundance, as suggested by
Dawson et al. (2013). Given the broad range of times since introduction, we hypothesized that the most recent introductions would be the least impactful, or conversely, our oldest agronomic crops would have undergone extensive breeding and selection, reducing their impact scores. Neither conclusion was validated. Our results agree that model outcomes are primarily driven by the establishment-spread portion of the model, with a history

Table 3. Weed risk assessment scores and results for candidate bioenergy crops, using the new U.S. (US-WRA) and Australian (AWRA) models.

\begin{tabular}{lllll}
\hline & & \multicolumn{2}{c}{ US-WRA } & \\
\cline { 3 - 4 } Scientific name & Common name & Result & Secondary screening & A-WRA result \\
\hline Arundo donax & Giant reed & High risk & - & Reject \\
Camelina sativa & Largeseed falseflax & Evaluate further & Evaluate further & Reject \\
Miscanthus sacchariflorus & Amur silvergrass & Evaluate further & High risk & Reject \\
Miscanthus sinensis & Eulaliagrass & High risk & - & Reject \\
Miscanthus $\times$ giganteus $($ sterile) & Giant Miscanthus & Low risk & - & Evaluate further \\
Miscanthus $\times$ giganteus $($ fertile) & Powercane & Evaluate further & Evaluate further & Reject \\
Panicum virgatum & Switchgrass & Evaluate further & Evaluate further & Reject \\
Sorghum bicolor & Sorghum & High risk & - & Reject \\
Pennisetum purpureum & Napiergrass & Evaluate further & High risk & Reject \\
Phalaris arundinacea & Reed canarygrass & High risk & - & Reject \\
Saccharum spontaneum & Wild sugarcane & High risk & - & Reject \\
Thlaspi arvense & Field pennycress & High risk & - & Reject \\
Eucalyptus globulus & Tasmanian blue gum & High risk & - & Reject \\
Jatropha curcas & Barbados nut & Evaluate further & High risk & Reject \\
Paulownia tomentosa & Royal paulownia & Evaluate further & High risk & Reject \\
Robinia pseudoacacia & Black locust & High risk & - & Reject \\
Triadica sebifera & Chinese tallowtree & High risk & - & Reject \\
\hline
\end{tabular}


of invasion elsewhere being the most important driver (Koop et al. 2012).

\section{Discussion}

Our most important agricultural crops are exotic species introduced, domesticated, and widely cultivated to meet our food, feed, fiber, construction, and energy needs (Sax et al. 2005). Charges and fears of invasiveness should not be based on nativeness (Davis et al. 2011), rather the primary determinant should be the likelihood that a new introduction will cause more harm than benefit (e.g., Yokomizo et al. 2012). This potential ecological vs. economic antagonism makes predicting invasiveness and regulatory decisions inherently difficult (Cousens 2008).

Risky Guesses? Our results show that WRAs differ in their assessment and tolerance of risk, and do not pragmatically handle large, intraspecific variation. The high number of high risk/reject scores for both models was surprising, especially for the agronomic crops. Importantly, had we not assessed crops and invasives in conjunction with candidate bioenergy feedstocks, our conclusions may have been altogether different: do not cultivate the high-risk bioenergy crops. However, comparing species that vary in invasiveness, critical for the interpretation of relevant studies (e.g., Smith and Barney 2014), clearly indicates that both models failed to effectively parse the weeds from the crops (Figure 1). All species have some probability of becoming invasive (Smith and Barney 2014), yet a model that places cereal rye (Secale cereale L.) between the widespread and damaging invaders, kudzu and cogongrass, must be questioned for its ability to drive policy decisions, especially when potentially economically valuable, novel crops are concerned (Barney 2014).

It is surprising that some crops have a higher US-WRA impact score than several common invasive species (Table 2). We offer two explanations for why the crops have surprisingly high-risk outcomes. First, the WRAs are unable to account for high, intraspecific variation, including important functional trait differences within a species. Importantly, we conducted each WRA at the species level. For example, sorghum [Sorghum bicolor (L.) Moench ssp. bicolor] and shattercane [Sorghum bicolor (L.) Moench ssp. arundinaceum (Desv.) de Wet \& Harlan] vary in seed shattering, seed dormancy, seed longevity, and plant height-differences which favor shattercane persistence (Fellows and Roeth 1992). In our analysis of S. bicolor, any information for shattercane was included in the analysis for grain sorghum since they are the same species. WRAs are traditionally conducted at the species level (Gordon et al. 2010), and crops appear to present a challenge to WRA analyses as the level of infraspecific variation can be quite high, especially given the development of diverse cultivars or hybrids (Martin et al. 2006).
However, it is not at all clear how WRAs could incorporate such variation reliably. For example, Miscanthus sinensis has been considered both as a bioenergy crop but more likely as potential germplasm for breeding programs. More than 100 named varieties of ornamental Miscanthus spp. have been introduced to the United States since the late 1800s and are widely available for purchase (Quinn et al. 2010). Yet, varieties of $M$. sinensis show remarkable differences in reproductive potential (Meyer and Tchida 1999; Smith et al. 2015); differences that are not evident by performing a single risk assessment at the species level. Considering the numerous varieties of many of our agricultural commodities, evaluation at the cultivar level would not only be impractical but subtle differences in traits may not be well studied or successfully conveyed by the WRA models. Functional traits have an important role in invasiveness (Cousens 2008; van Kleunen et al. 2010), but important subtleties belie our ability to use them predictively, except in rare circumstances (e.g., Rejmanek and Richardson 1996).

Second, strikingly little data exist on the ecological impacts of invasive plants (Barney et al. 2013), whereas crops tend to be well studied, especially their weedy escapes (e.g., Pekrun et al. 2005). We agree that impact should have a primary role in risk determination by the WRAs, serving as a risk axis in the US-WRA. However, given that the impact for most invasives remains unstudied (Hulme et al. 2013), let alone for new species or crops, does it make sense to use impact as a predictive variable? How should we treat noninvasives and invasives that have similar WRA impact scores but for different reasons: one causes no impact, and the other is just unmeasured? Current WRAs are unable to reckon such important challenges.

As discussed, these models were designed and calibrated (Hulme 2012) for taxa that are not regularly subject to intensive management (i.e., annual harvest). Grower decisions that could directly influence propagule pressure and establishment success are largely different for agricultural crops than they are for horticultural and landscape plantings. Altering models to incorporate management or a combination of management strategies (i.e., reduce propagule pressure, harvest timing) could lower the overall risk score suggested by our outcome of the risk of sterile Miscanthus $\times$ giganteus being lower than that of the fertile cultivars. However, management implementation is left to the trust and reliability of the industry, which may be insufficient or too inconsistent to overcome known risks.

WRAs result in categorical outcomes of invasiveness, typically applied across large, heterogeneous landscapes (Koop et al. 2012). However, in reality, invasiveness is a continuous property that can easily change based on a number of contingencies (Barney and Whitlow 2008). For example, $A$. donax was intentionally introduced into riparian areas for bank stabilization and erosion control 
in the southwestern United States (Bell 1997) and had a robust source of vegetative propagules easily transportable along waterways, which resulted in invasion (Quinn and Holt 2008). Proper field siting could greatly reduce escape risk in the southeast and elsewhere, that is, away from riparian areas, which appear to be the primary means of dispersal.

Some have applied WRAs at smaller, more climatically homogenous spatial scales (e.g., Buddenhagen et al. 2009; Gordon et al. 2011). However, WRA outcomes may be inappropriately applied even at this resolution, which includes heterogeneous landscapes varying in invasibility (Cousens 2008; Smith and Barney 2014). Even in high-risk scenarios, in some circumstances, landscape and crop management can effectively mitigate risk (Buckley et al. 2005); considerations that WRAs do not consider. Therefore, climate appropriateness, spatiotemporal grain size, and management scenarios are existing challenges to the robustness of existing WRAs (Hulme 2012b).

A Folly of (In)Appropriate Risk Assessment. Economic projections show the A-WRA has a net positive economic benefit to Australia (Keller et al. 2007). Unfortunately, commercial species were not considered, and blacklisting many agronomic species would be economically ruinous. The US-WRA has managed to address the false-positive species (benign species labeled invasive) to some level, but if we are going to take these scores at face value, the inability to perfectly separate weeds from crops must be judged. For example, no ecologist, agronomist, or conservationist would suggest a ban on rice cultivation for fear of potential escapes! When it comes to economically important crops, a WRA system that ranks crops, such as rice, barley, and alfalfa (Medicago sativa L.), among some of our most-devastating invasive weeds (Figure 1) lacks the ability to address important socioeconomic issues. Broader considerations, including economic revitalization, alternative energy choices, climate change, and sustainability, especially at the local scale, must be part of the dialogue. However, accounting for nonecological variables is a challenge that needs to be met to address important socioeconomic-ecological issues.

In an attempt to address these challenges, some have called for a tiered risk assessment approach, with WRA models serving as the starting point (Barney 2014; Cousens 2008; Davis et al. 2010; Quinn et al. 2013). However, based on our findings a tiered approach would eliminate $77 \%$ of the bioenergy feedstocks and five agronomic crops at the first tier (Tables 2 and 3; Davis et al. 2010). The tiered systems address some of the predictive limitations of the WRAs but do not address the challenges we present above. Others have suggested adopting horticultural practices of selecting specific cultivars for extensive observational field trials (Cousens 2008; Mack 2005). Although informative, that would be a timely and expensive process, especially for perennial species.

This exercise was not intended to address or repair all shortcomings of WRAs nor did we assess all possible crops, biofuels, or invasive species. Our aim rather, was to evaluate candidate bioenergy crops, as a subset of species introduced in the agricultural pathway and to determine the rigor of WRAs in their evaluation of new crops. Based on the results of both models in assessing important agronomic crops, a "white list" of crops developed from risk assessment alone could not only be economically devastating, but introduces the potential to create regulatory loopholes in state and federal noxious-weed laws. For example, Quinn et al. (2015) propose a list of low-risk taxa (25 of which are exotic) based on WRA results, which include known invaders like Spartina spp. Just as we found some crops to be rated high risk by the WRAs that we recognize as safer in practice, assuming that species are inherently safe in all scenarios is equally unrealistic.

As they stand, WRAs should not be the singular element in risk management when novel crops are concerned (Cousens 2008). An inclusive cost-benefit analysis that addresses economic, ecological, and social advantages and disadvantages, grounded in ecological theory that integrates the body of invasion science would attend to the broader risk ledger when introducing and cultivating exotic species. For example, the cost-benefit analysis devised by Yokomizo et al. (2012) uses information-gap theory to evaluate when commercial value of an introduction outweighs potential impacts under high uncertainty, an important step in this direction.

Without adopting an extreme policy, such as restricting the cultivation of new crops to native plants, we will never truly reduce the risk of invasive accessions. In the same way the precautionary principle has been applied to genetically modified crops (CAST 2013), our fear of widespread bioenergy crop adoption may be less detrimental than our failure to develop sustainable sources of alternative energy. Introductions of new species should not be met with reckless abandon, but our current level of knowledge requires careful and balanced evaluation beyond qualitative risk assessments. Clearly, weed risk assessments must become a transdisciplinary effort to achieve management and policy goals to protect our natural capital while balancing economic growth.

\section{Acknowledgments}

We would like to thank Anthony Koop and colleagues at APHIS's Plant Epidemiology and Risk Analysis Laboratory for materials and training in the use of their weed risk assessment tool. We also thank Dan Atwater, two anonymous reviewers, the Associate Editor, and the Editor for valuable comments on an earlier draft. 


\section{Literature Cited}

Barney JN (2014) Bioenergy and invasive plants: quantifying and mitigating future risks. Invasive Plant Sci Manage 7:199-209

Barney JN, DiTomaso JM (2008) Non-native species and bioenergy: are we cultivating the next invader? Bioscience 58:64-70

Barney JN, Smith LL, Tekiela DR (2015) Using weed risk assessments to separate the weeds from the crops. Pages 67-84 in Quinn LD, Matlaga DP, Barney JN, eds. Bioenergy and Biological Invasions: Ecological, Agronomic and Policy Perspectives on Minimising Risk. Oxford, U.K.: CABI

Barney JN, Tekiela D, Dollete E, Tomasek B (2013) What is the "real" impact of invasive plant species? Front Ecol Environ 11:322-329

Barney JN, Whitlow TH (2008) A unifying framework for biological invasions: the state factor model. Biol Invasions 10:259-272

Bell GP (1997) Ecology and management of Arundo donax, and approaches to riparian habitat restoration in Southern California. Pages 103-113 in Brock J H, Wade M, Pysek P, Green D, eds. Plant Invasions: Studies from North America and Europe. Leiden, The Netherlands: Blackhuys

Buckley YM, Brockerhoff E, Langer L, Ledgard N, North H, Rees M (2005) Slowing down a pine invasion despite uncertainty in demography and dispersal. J Appl Ecol 42:1020-1030

Buddenhagen CE, Chimera C, Clifford P (2009) Assessing biofuel crop invasiveness: a case study. PLoS One 4:e5261. DOI: 10.1371/ journal.pone.0005261

[CAST] Council for Agricultural Science and Technology (2013) Impact of the precautionary principle on feeding current and future generations. Ames, Iowa: CAST Issue Paper 52

Cousens R (2008) Risk assessment of potential biofuel species: an application for trait-based models for predicting weediness. Weed Sci 56:873-88

Daehler CC, Denslow JS, Ansari S, Kuo H (2004) A risk-assessment system for screening out invasive pest plants from Hawaii and other Pacific Islands. Conserv Biol 18:360-368

Davis AS, Cousens RD, Hill J, Mack RN, Simberloff D, Raghu S (2010) Screening bioenergy feedstock crops to mitigate invasion risk. Front Ecol Environ 8:533-539

Davis MA, Chew M, Hobbs R, Lugo A, Ewel J, Vermeij G, Brown J, Rosenzweig M, Gardner M, Carroll S, Thompson K, Pickett S, Stromberg J, Del Tredici P, Suding KN, Ehrenfeld JG, Grime J, Mascaro J, Briggs J (2011) Don't judge species on their origins. Nature 474:153-154

Dawson W, Keser LH, Winter M, Pysek P, Kartesz J, Nishino M, Fuentes N, Chytry M, Celesti-Grapow L, Van Kleunen M (2013) Correlations between global and regional measures of invasiveness vary with region size. Neobiota 16:59-80

Dostál P, Müllerová J, Pyšek P, Pergl J, Klinerová T, Vila M (2013) The impact of an invasive plant changes over time. Ecol Lett 16: $1277-1284$

Dougherty RF, Quinn L, Endres A, Voigt T, Barney JN (2014) Natural history survey of the ornamental grass Miscanthus sinensis in the invaded range. Invasive Plant Sci Manag 7:113-120

Driscoll DA, Catford JA, Barney JN, Hulme PE, Inderjit, Martin TG, Pauchard A, Pyšek P, Richardson DM, Riley S, Visser V (2014) New pasture plants intensify invasive species risk. Proc Natl Acad Sci U S A 111:16622-16627

Eiswerth ME, Van Kooten GC (2000) Uncertainty, economics and the spread of an invasive species plant. Am J Agric Econ 84:1317-1322

Fellows GM, Roeth FW (1992) Factors influencing shattercane (Sorghum bicolor) seed survival. Weed Sci 40:434-440

Glaser A, Glick P (2012) Growing Risk: Addressing the Invasive Potential of Bioenergy Feedstocks. Washington, DC: National Wildlife Federation
Gordon DR, Mitterdorfer B, Pheloung PC, Ansari S, Buddenhagen C, Chimera C, Daehler CC, Dawson W, Denslow JS, Larosa A, Nishida T, Onderdonk DA, Panetta FD, Pysek P, Randall RP, Richardson DM, Tshidada NJ, Virtue JG, Williams PA (2010) Guidance for addressing the Australian weed risk assessment questions. Plant Prot Q 25:56-74

Gordon DR, Onderdonk DA, Fox AM, Stocker RK (2008) Consistent accuracy of the Australian weed risk assessment system across varied geographies. Divers Distrib 14:234-242

Gordon DR, Tancig KJ, Onderdonk DA, Gantz CA (2011) Assessing the invasive potential of biofuel species proposed for Florida and the United States using the Australian weed risk assessment. Biomass Bioenerg 35:74-79

Holm LG, Plucknett DL, Juan PV, Herberger JP (1977) The World's Worst Weeds: Distribution and Biology. Honolulu: University Press of Hawaii

Hulme PE (2012) Weed risk assessment: a way forward or a waste of time? J Appl Ecol 49:10-19

Hulme PE, Pysek P, Jaroaik VC, Pergl J, Schaffner U, Villa M (2013) Bias and error in understanding plant invasion impacts. Trends Ecol Evol 28:212-218

Keller RP, Lodge DM, Finnoff DC (2007) Risk assessment for invasive species produces net bioeconomic benefits. Proc Nat Acad Sci U S A 104:203-207

Koop A, Fowler L, Newton L, Caton B (2012) Development and validation of a weed screening tool for the United States. Biol Invasions 14:273-294

Lewandowski I, Scurlock JMO, Lindvall E, Christou M (2003) The development and current status of perennial rhizomatous grasses as energy crops in the US and Europe. Biomass Bioenerg 25:335-361

Lewis KC, Porter RD (2014) Global approaches to addressing biofuelrelated invasive species risks and incorporation into U.S. laws and policies. Ecol Monogr 84:171-201

Lonsdale WM (2011) Risk assessment and prioritization. Pages 604-609 in Simberloff D, Rejmanek M, eds. Encyclopedia of Biological Invasions. Berkeley: University of California Press

Mack RN (2005) Predicting the identity of plant invaders: future contributions from horticulture. Hortscience 40:1168-1174

Martin J, Waldren R, Stamp D (2006) Principles of Field Crop Production. Upper Saddle River, NJ: Prentice Hall

Mcneely JA, Neville LE, M. R (2003) When is eradication a sound investment? Conserv Pract 4:30-41

Meyer MH, Tchida CL (1999) Miscanthus Andress. produces viable seed in four USDA hardiness zones. J Environ Hortic 17:137-140

Molina-Montenegro MA, Carrasco-Urra F, Rodrigo C, Valladares F, Gianoli E (2012) Occurrence of the non-native annual bluegrass on the Antarctic mainland and its negative effects on native plants. Conserv Biol 26:717-723

Nishida T, Yamashita N, Asia M, Kurokawa S, Enomoto T, Pheloung PC, Groves RH (2009) Developing a pre-entry weed risk assessment system for use in Japan. Biol Invasions 11:1319-1333

Panetta FD (2009) Weed eradication-an economic perspective. Invasive Plant Sci Manage 2:360-368

Peel MC, Finlayson BL, Mcmahon TA (2007) Updated world map of the Köppen-Geiger climate classification. Hydrol Earth Syst Sci 11: 1633-1644

Pekrun C, Lane P, Lutman P (2005) Modelling seedbank dynamics of volunteer oilseed rape (Brassica napus). Agric Syst 84:1-20

Perlack RD, Wright LL, Turhollow AF, Graham RL, Stokes BJ, Erbach DC (2005) Biomass as feedstock for a bioenergy and bioproducts industry: the technical feasibility of a billion-ton annual supply. Oak Ridge, TN: Oak Ridge National Laboratory Tech Rep ORNL/TM2006/66

Pheloung PC, Williams PA, Halloy SR (1999) A weed risk assessment model for use as a biosecurity tool evaluating plant introductions. J Environ Manage 57:239-251 
Pimentel D, Lach L, Zuniga R, Morrison D (2000) Environmental and economic costs of nonindigenous species in the United States. Bioscience 50:53-65

Quinn L, Allen DJ, Stewart R (2010) Invasiveness potential of Miscanthus sinensis: implications for bioenergy production in the United States. Glob Change Biol Bioenergy 2:310-320

Quinn L, Barney J, Mccubbins J, Endres A (2013) Navigating the "noxious" and "invasive" regulatory landscape: suggestions for improved regulation. Bioscience 63:124-131

Quinn LD, Gordon DR, Glaser A, Lieurance D, Flory SL (2015) Bioenergy feedstocks at low risk for invasion in the USA: a "white list" approach. Bioenerg Res 8:471-481. DOI: 10.1007/s12155-014-9503-z

Quinn LD, Holt JS (2008) Ecological correlates of invasion by Arundo donax in three southern California riparian habitats. Biol Invasions 10:591-601

Raghu S, Anderson RC, Daehler CC, Davis AS, Wiedenmann RN, Simberloff D, Mack RN (2006) Adding biofuels to the invasive species fire? Science 313:1742

Rejmanek M, Richardson DM (1996) What attributes make some plant species more invasive? Ecology 77:1655-1660

Robertson GP, Dale VH, Doering OC, Hamburg SP, Melillo JM, Wander MM, Parton WJ, Adler PR, Barney JN, Cruse RM, Duke CS, Fearnside PM, Follett RF, Gibbs HK, Goldemberg J, Mladenoff DJ, Ojima D, Palmer MW, Sharpley A, Wallace L, Weathers KC, Wiens JA, Wilhelm WW (2008) Sustainable biofuels redux. Science 322:49-50

Sax DF, Stachowicz JJ, Gaines SD, eds (2005) Species Invasions: Insights into Ecology, Evolution, and Biogeography. Sunderland, MA: Sinauer Seawright EK, Rister ME, Lacewell RD, Mccorkle DA, Sturdivant AW, Yang C, Goolsby JA (2009) Economic implications for the biological control of Arundo donax: Rio Grande Basin. Southwest Entomol 34: 377-394

Simberloff D (2005) The politics of assessing risk for biological invasions: the USA as a case study. Trends Ecol Evol 20:216-222
Simberloff D (2008) Invasion biologists and the biofuels boom: Cassandras or colleagues? Weed Sci 56:867-872

Smith LL, Allen DJ, Barney JN (2015) The thin green line: sustainable bioenergy feedstocks or invaders in waiting? Neobiota 25:47-71

Smith LL, Barney JN (2014) The relative risk of invasion: evaluation of Miscanthus $\times$ giganteus seed establishment. Invasive Plant Sci Manage 7:93-106

Stone LM, Byrne M, Virtue JG (2008) An environmental weed risk assessment model for Australian forage improvement programs. Aust J Exp Agric 48:568-574

Van Kleunen M, Weber E, Fischer M (2010) A meta-analysis of trait differences between invasive and non-invasive plant species. Ecol Lett $13: 235-245$

Vilà M, Espinar JL, Hejda M, Hulme PE, Jarošík V, Maron JL, Pergl J, Schaffner U, Sun Y, Pyšek P (2011) Ecological impacts of invasive alien plants: a meta-analysis of their effects on species, communities and ecosystems. Ecol Lett 14:702-708

Virtue JG, Bennett SJ, Randall RP (2004) of Conference. Plant introductions in Australia: how can we resolve weedy conflicts of interest? Pages 42-48 in Sindel BM, Johnson SB, eds. Proceedings of Weed Management: Balancing People, Planet, Profit-the 14th Australian Weeds Conference. Sydney, Australia: Weed Society of New South Wales

Warwick SI, Black LD (1983) The biology of Canadian weeds. 61. Sorghum halepense (L.) PERS. Can J Plant Sci 63:997-1014

Williamson M, Fitter A (1996) The varying success of invaders. Ecology 77:1661-1666

Yokomizo H, Possingham HP, Hulme PE, Grice AC, Buckley YM (2012) Cost-benefit analysis for intentional plant introductions under uncertainty. Biol Invasions 14:839-849

Received January 19, 2015, and approved May 12, 2015.

Associate Editor for this paper: Stephen F. Enloe, University of Florida. 